\title{
Interacting Effects of Photoperiod and Photosynthetic Photon Flux on Net Carbon Assimilation and Starch Accumulation in Potato Leaves
}

\author{
Gary W. Stutte and Neil C. Yorio \\ Dynamac Corporation, Mail Code DYN-3, Kennedy Space Center, FL 32899
}

\author{
Raymond M. Wheeler \\ Office of Biomedical Operations, The National Aeronautics and Space Administration, Kennedy Space \\ Center, FL 32899
}

\begin{abstract}
Additional index words. advanced life support, controlled ecological life support system, CELSS, carbohydrate metabolism, controlled environment, photosynthesis, Solanum tuberosum
\end{abstract}

\begin{abstract}
The effect of photoperiod (PP) on net carbon assimilation rate ( $\left.\mathrm{A}_{\mathrm{net}}\right)$ and starch accumulation in newly mature canopy leaves of 'Norland' potato (Solanum tuberosum L.) was determined under high $\left(412 \propto \mathrm{mol}^{\circ} \cdot \mathrm{m}^{-2} \cdot \mathrm{s}^{-1}\right)$ and low ( 263 $\propto \mathrm{mol} \cdot \mathrm{m}^{-2} \cdot \mathrm{s}^{-1}$ ) photosynthetic photon flux (PPF) conditions. The $A_{\text {net }}$ decreased from 13.9 to 11.6 and $9.3 \mu \mathrm{mol} \cdot \mathrm{m}^{-2} \cdot \mathrm{s}^{-1}$, and

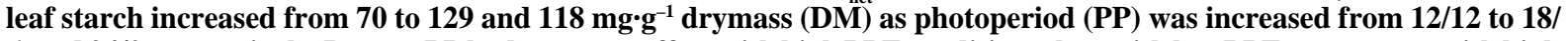
6, and 24/0, respectively. Longer PP had a greater effect with high PPF conditions than with low PPF treatments, with high PPF showing greater decline in $\mathrm{A}_{\text {net }}$. Photoperiod did not affect either the $\mathrm{CO}_{2}$ compensation point $\left(50 \mu \mathrm{mol}^{-} \cdot \mathrm{mol}^{-1}\right)$ or CO$_{2}$ saturation point $\left(1100-1200 \mu \mathrm{mol}^{-\mathrm{mol}^{-1}}\right)$ for $A_{\text {net }}$. These results show an apparent limit to the amount of starch that can be stored $(\approx 15 \% \mathrm{DM})$ in potato leaves. An apparent feedback mechanism exists for regulating $A_{\text {net }}$ under high PPF, high $\mathrm{CO}_{2}$, and long PP, but there was no correlation between $\mathrm{A}_{\text {net }}$ and starch concentration in individual leaves. This suggests that maximum $A_{\text {net }}$ cannot be sustained with elevated $\mathrm{CO}_{2}$ conditions under long $P P(\geq 12$ hours $)$ and high PPF conditions. If a physiological limit exists for the fixation and transport of carbon, then increasing photoperiod and light intensity under high $\mathrm{CO}_{2}$ conditions is not the most appropriate means to maximize the yield of potatoes.
\end{abstract}

Long duration space missions will likely require the use of bioregenerative life-support systems to generate oxygen, purify water, remove carbon dioxide, produce food, and recycle waste materials (MacElroy and Bredt, 1985; Olson et al., 1988; Salisbury and Bugbee, 1988). Potatoes, which have been identified as a candidate crop for inclusion in a controlled ecological advanced life-support system (CELSS), have been the subject of study for several years (Tibbitts et al., 1993). Within a CELSS, total irradiance has been suggested to be the largest limitation to crop productivity (Salisbury and Bugbee, 1988; Wheeler and Tibbitts, 1986a, 1986b). We can expect to improve yield by increasing the net daily integral of photosynthetically active radiation (PAR) through higher irradiance or longer photoperiod.

It is generally accepted that long photoperiods inhibit tuber initiation and promote potato shoot growth (Gregory, 1965). However, it has been reported that tuber initiation is inhibited only at low light levels (Tibbitts et al., 1993; Wheeler et al., 1991). Therefore, yields are typically higher for field grown plants produced under long, rather than short photoperiods with the relatively high total irradiance received under long day conditions (Wheeler and Tibbitts, 1986b) .

Since the photoperiod response of potato tuberization was initially reported (Auchter and Harley, 1924; Garner and Allard, 1923), a role for starch in the regulation of photosynthesis, and thus yield, has been postulated. Although subject to intense investiga-

Received for publication 8 May 1995. Accepted for publication 19Sept. 1995. This research was conducted under the auspices of Biomedical Operations and Research Office, John F. Kennedy Space Center, Fla. We wish to thank Elizabeth Stryjewski, Cheryl Mackowiak, and Lisa Ruffe of the Dynamac corporation for their support of this project. Mention of a trademark, proprietary product or vendor does not constitute an endorsement of the product by either The Dynamac Corporation, or NASA. The cost of publishing this paper was defrayed in part by the payment of page charges. Under postal regulations, this paper therefore must be hereby marked advertisement solely to indicate this fact. tion, the effects of irradiance, $\mathrm{CO}_{2}$ concentration, and temperature on starch accumulation and photosynthetic action have not been fully explained at the whole-plant level (Geiger and Fondy, 1991; Herold, 1980; Neales and Incoll, 1968).

Leaf necrosis has been reported in potato exposed to continuous light (Wheeler and Tibbitts, 1986b). Cao and Tibbitts (1991) reported that starch was not correlated to continuous light damage in susceptible cultivars. Starch accumulation in potato leaves (Lorenzen and Ewing, 1992) was greater under long photoperiods than short photoperiods, even with the presence of a strong sink (e.g., expanding tubers). Although yield enhancement under long days is generally assumed to be related to greater carbon assimilation, there are few reports of the effect of photoperiod on net carbon assimilation of potato leaves.

Our objectives were to establish whether long photoperiod at different PPF levels would affect net carbon assimilation rate $\left(\mathrm{A}_{\text {net }}\right)$ of potato leaves, and to determine whether photoperiod affects the concentration of starch in the leaves.

\section{Materials and Methods}

Plant growing conditions. 'Norland' potato(Solanum tuberosum), an early maturing, continuous light tolerant cultivar was used in this experiment. Plantlets were initiated from in vitro nodal culture and grown using a recirculating nutrient film technique (NFT) with a modified half strength Hoagland's solution (Wheeler et al., 1990). Plant growth chambers (model M12; EGC, Chagrin Falls, Ohio) were configured to provide either $600 \mu \mathrm{mol} \cdot \mathrm{m}^{-2} \cdot \mathrm{s}^{-1} \mathrm{PPF}$ (High Light, $\mathrm{HL}$ ) or $300 \mu \mathrm{mol} \cdot \mathrm{m}^{-2} \cdot \mathrm{s}^{-1} \mathrm{PPF}$ (Low Light, LL) with four $400 \mathrm{~W}$ metal halide lamps (Pro-Arc, Venture Lighting, Cleveland, Ohio). The mean PPF valves at canopy level during testing periods are provided in the results.

Environmental conditions in each plant growth chamber con-

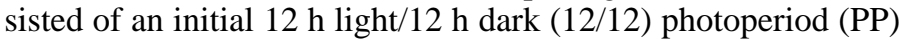


with a matching thermoperiod of $20 / 16 \pm 0.2 \mathrm{C}$ and constant relative humidity of $65 \% \pm 6 \%$. Atmospheric $\mathrm{CO}_{2}$ concentrations were maintained at $1200 \pm 10 \mu \mathrm{mol} \cdot \mathrm{mol}^{-1}$ with an infrared gas analyzer (Anarad AR600, Santa Barbara, Calif.) and dedicated computer control system. Daily records of water use, acid additions for $\mathrm{pH}$ control, and nutrient replenishment solution additions were maintained. Weekly measures of photosynthetic photon flux (PPF) at the plant canopy were taken. At harvest, plants were separated into shoots (leaves and stems), roots, and tubers. Fresh mass (FM) of tissues was recorded before oven drying for $72 \mathrm{~h}$ at $70 \mathrm{C}$ for dry mass (DM) determination.

Photoperiod treatments. At 56 days after planting (DAP), the photoperiod was changed from $12 / 12$ to $18 \mathrm{~h}$ light/6 h dark (18/6). The plants were allowed to adapt to the photoperiod for $36 \mathrm{~h}$ before gas exchange and starch measurements were determined. At 63 DAP the photoperiod was changed to $24 \mathrm{~h}$ light/0 h dark (24/0). Following each photoperiod adjustment, the photoperiod was cycled to $12 / 12$. It is recognized that the age of the plant was different during each photoperiod treatment, but care was taken to sample leaves of similar phylogenetic age.

Photosynthetic measurements. Diurnal measurements of the net $\mathrm{CO}_{2}$ assimilation rate $\left(\mathrm{A}_{\text {net }}\right)$ were performed on recently mature single leaves in the upper canopy using a closed leaf cuvette photosynthesis system (Model LI-6200; Li-Cor, Lincoln, Neb.) The $\mathrm{A}_{\text {net }}$ vs. $\mathrm{CO}_{2}$ internal $\left(\mathrm{A}_{\mathrm{Ci}}\right)$ curves and $\mathrm{CO}_{2}$ compensation point were determined at about $1 \mathrm{~h}$ after lights came on for each of the photoperiod tests (McDermitt et al, 1988). Fresh mass (FM), leaf area (LA), and dry mass (DM) were obtained for the portion of leaves measured during the carbon exchange rate (CER) tests. This tissue was subsequently used for starch analysis.

Starch analysis. Starch concentration of potato leaves used for diurnal photosynthetic measurements were analyzed using a modification of the method of Wang and Stutte (1992). Oven-dried tissue was ground with a mortar and pestle, and samples (20-100 $\mathrm{mg}$ ) were extracted three times for $10 \mathrm{~min}$ each in boiling $80 \%$ ethanol to remove soluble sugars and chlorophyll. The samples were centrifuged, and pellets were resuspended in $0.1 \mathrm{M}$ acetate buffer, $\mathrm{pH}$ 4.6, and boiled for $10 \mathrm{~min}$ to swell and gelatinize the pellets. Standards of potato starch (Sigma Chemical Co., St. Louis) up to $4.0 \mathrm{mg}$ were run with the samples. To digest the starch, amyloglucosidase was added to samples and standards and incubated in a water bath at $55 \mathrm{C}$ for $30 \mathrm{~min}$. The supernatant was assayed colorimetrically for conversion of starch to glucose using glucose oxidase (Sigma Diagnostics, St. Louis). When original digests yielded starch concentrations greater than $4.0 \mathrm{mg} / \mathrm{sample}$, the procedure was repeated on the undigested pellet and starch concentrations from multiple digests were summed together. The final starch concentration per sample was expressed as $\mathrm{mg}$ starch/ $\mathrm{g}$ leaf DM or $\mathrm{mg} \mathrm{starch} / \mathrm{cm}^{2} \mathrm{LA}$.

\section{Results}

\section{Net carbon assimilation}

Light intensity. As expected, $\mathrm{A}_{\text {net }}$ of recently mature leaves grown under $\mathrm{HL}$ conditions was higher than $\mathrm{A}_{\text {net }}$ of leaves grown under LL conditions (Table 1). The dark period respiration rate (Rs) of the HL leaves was higher than Rs of the LL leaves. The greater Rs of the HL treatment may partially result from the greater specific leaf weight (SLW) of the HL than LL leaves.

Photoperiod. Changing the PP from 12/12 to $18 / 6$ resulted in a $16 \%$ decrease in the instantaneous $\mathrm{A}_{\text {net }}$ and a $23 \%$ decrease in Rs. Exposing the plants to continuous lighting conditions for $36 \mathrm{~h}$ resulted in a $33 \%$ decrease from $12 / 12$ in $A_{\text {net }}$ (Table 1). Rs was not measured for the 24/0 treatment.

Diurnal response. The $\mathrm{A}_{\text {net }}$ of recently mature leaves did not vary significantly during the light cycle in either the $12 / 12$ or $18 / 6$ photoperiod treatments (Fig. 1). In contrast, variation in $\mathrm{A}_{\text {net }}$ increased when leaves were exposed to continuous lighting conditions. Under continuous illumination, individual leaves began to exhibit morphological changes, including localized chlorosis and necrosis, which could result in increased variation in $\mathrm{A}_{\text {net }}$ between leaves. In addition, the leaves exhibited slight epinasty and the accumulation of anthocyanin on the abaxial surface of the leaf. The morphological responses were similar to the continuous illumination injury described by Cao and Tibbitts (1991). The $\mathrm{A}_{\text {net }}$ values of leaves grown under $\mathrm{HL}$ conditions were comparable to $\mathrm{A}_{\text {net }}$ values previously reported for plants of comparable ages and grown under similar environmental conditions (Dwelle et al., 1983).

$\mathrm{CO}_{2}$ compensation and saturation. $\mathrm{CO}_{2}$ response curves were determined for each of the treatments and normalized to 400 $\mu \mathrm{mol} \cdot \mathrm{m}^{-2} \cdot \mathrm{s}^{-1}$ PPF based on PPF response curves (Fig. 2). The light response curves obtained from individual leaves used in these studies was linear $\left(\mathrm{y}=0.0436 \mathrm{x}-3.826 ; r^{2}=0.961\right)$ over the PPF range of 65 to $650 \mu \mathrm{mol} \cdot \mathrm{m}^{-2} \cdot \mathrm{s}^{-1}$. $A_{\text {net }}$ values of the HL treatment were greater than the LL treatment at $12 / 12$. The HL and LL treatment $A_{\text {net }}$ rates were similar at $18 / 6$ and $A_{\text {net }}$ of HL treatments

Table 1. Effects of photosynthetic photon flux (PPF) and photoperiod on net carbon assimilation and starch accumulation in recently mature 'Norland' potato leaves. Values represent the mean of all measurements taken during either the light or dark cycle for a respective treatment.

\begin{tabular}{|c|c|c|c|c|}
\hline \multirow[b]{2}{*}{ Treatment } & \multicolumn{2}{|c|}{$\begin{array}{c}\text { Carbon assimilation } \\
\left(\mu \mathrm{mol} \mathrm{CO} \mathrm{CO}_{2} / \mathrm{m}^{2} \text { per sec }\right)\end{array}$} & \multicolumn{2}{|c|}{$\begin{array}{r}\text { Starch concn } \\
\left(\mathrm{mg} \cdot \mathrm{g}^{-1} \mathrm{DM}\right)\end{array}$} \\
\hline & Light cycle & Dark cycle & Light cycle & Dark cycle \\
\hline \multicolumn{5}{|c|}{$P P F$} \\
\hline Low light ${ }^{\mathrm{Z}}$ & $9.92 \pm 0.37^{y}$ & $-0.86 \pm 0.14$ & $110.32 \pm 5.87$ & $83.50 \pm 15.21$ \\
\hline High light & $12.57 \pm 0.69$ & $-1.29 \pm 0.10$ & $105.31 \pm 5.50$ & $90.03 \pm 10.90$ \\
\hline \multicolumn{5}{|c|}{ Photoperiod } \\
\hline $12 / 12$ & $13.87 \pm 0.87$ & $-1.17 \pm 0.05$ & $70.02 \pm 8.46$ & $64.10 \pm 7.02$ \\
\hline $18 / 6$ & $11.63 \pm 0.68$ & $-0.90 \pm 0.18$ & $129.23 \pm 2.69$ & $132.08 \pm 8.06$ \\
\hline $24 / 0$ & $9.27 \pm 0.38$ & $--^{x}$ & $117.57 \pm 3.21$ & --- \\
\hline
\end{tabular}




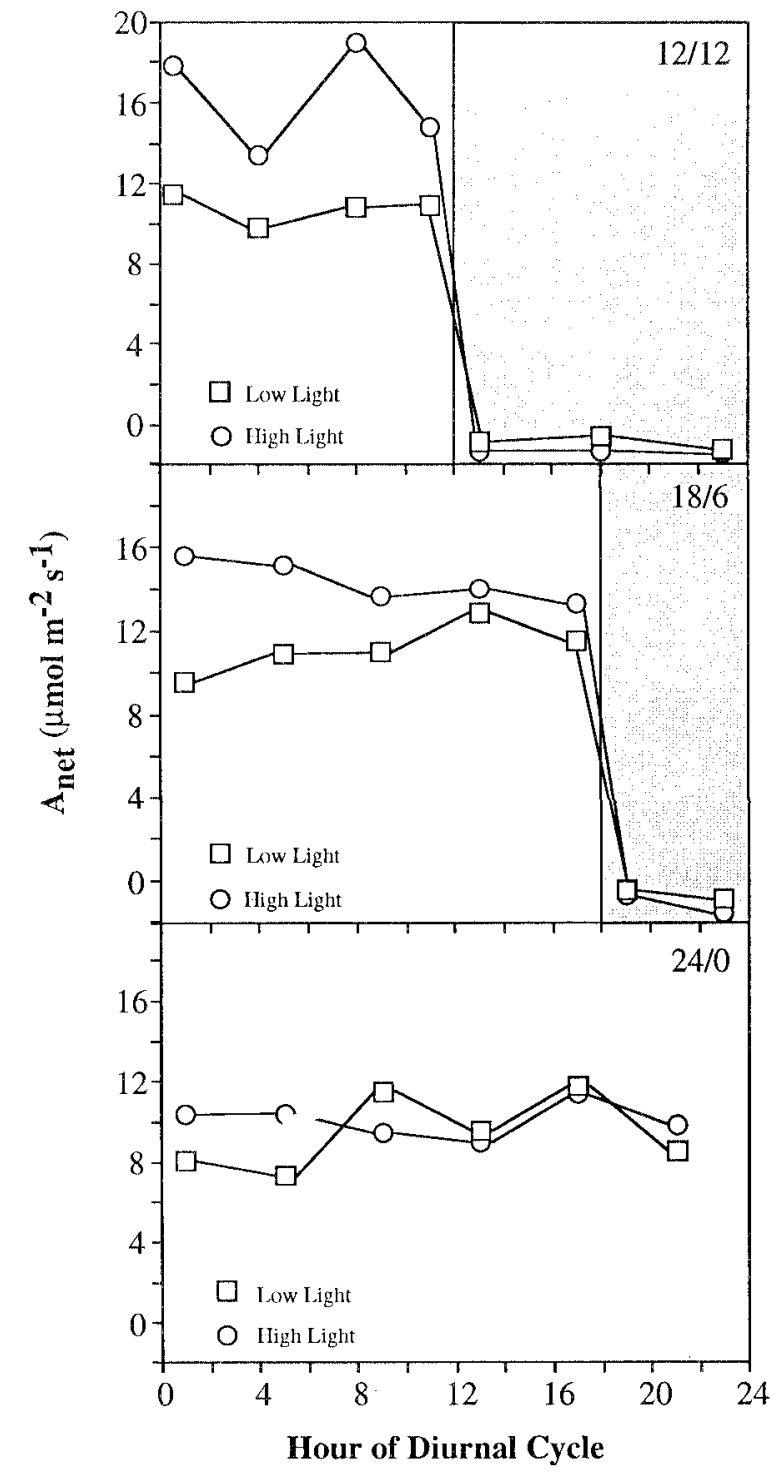

Fig. 1. Effect of PPF on diurnal changes in net carbon assimation rate of newly mature 'Norland' potato leaves exposed to different photoperiods. The mean PPF values were 263 and $412 \mu \mathrm{mol} \cdot \mathrm{m}^{-2} \cdot \mathrm{s}^{-1}$ in the low and high light chambers, respectively.

was less than $\mathrm{LL}$ at 24/0 PP (Fig. 2). The $\mathrm{CO}_{2}$ compensation point was about $50 \mu \mathrm{mol} \cdot \mathrm{mol}^{-1}$ and the $\mathrm{CO}_{2}$ saturation point was between 1100 and $1200 \mu \mathrm{mol} \cdot \mathrm{mol}^{-1}$, irrespective of light intensity or photoperiod treatment. The $\mathrm{CO}_{2}$ response curves were consistent with $\mathrm{A}_{\text {net }}$ values obtained during the diurnal sampling (Table $1)$.

\section{Starch analysis}

Light intensity. The mean leaf starch concentration during either the light or dark cycles was not affected by the light intensity treatment (Table 1).

Photoperiod. Increasing the PP from 12/12 to 18/6 significantly increased the leaf starch concentration during the light $(84 \%)$ and dark (106\%) cycles. Increasing the PP from $12 / 12$ to $24 / 0$ resulted in a similar increase (68\%) over $12 / 12$ in leaf starch concentration during the light cycle (Table 1).

Diurnal response. Under 12/12 PP, diurnal cycling of leaf starch concentration was observed, with accumulation occurring during the light cycle, and remobilization occurring during the dark cycle (Fig. 3 ). With the $18 / 6 \mathrm{PP}$, concentration of leaf starch at the end of the dark

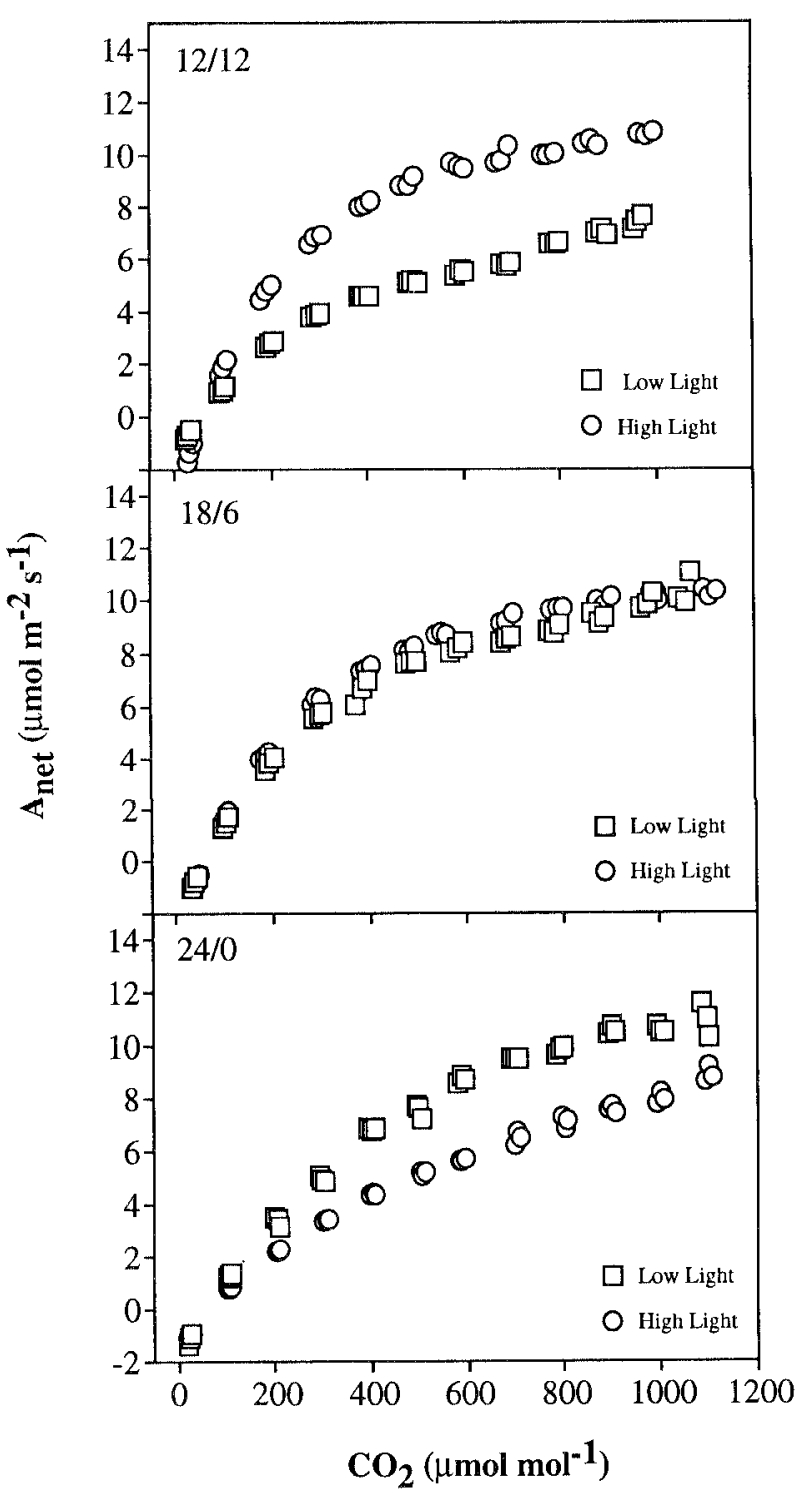

Fig. 2. Effect of $\mathrm{CO}_{2}$ concentration on net carbon assimilation of newly mature 'Norland' potato leaves exposed to different photoperiods. The mean PPF values were 263 and $412 \mu \mathrm{mol} \cdot \mathrm{m}^{-2} \cdot \mathrm{s}^{-1}$ in the low and high light chambers, respectively.

cycle increased as the length of the dark cycle decreased, although the change was small. Under continuous lighting, the concentration of starch in the leaves was about $12 \%$ of dry mass. Under a $12 / 12 \mathrm{PP}$, the starch concentration of leaves ranged from 20 to $120 \mathrm{mg} / \mathrm{g}$ leaf DM under LL conditions, but $A_{\text {net }}$ was constant at $12 \mu \mathrm{mol} \cdot \mathrm{m}^{-2} \mathrm{~s}^{-1}$ during the light cycle. In contrast, both the starch concentration $(85-120 \mathrm{mg} /$ g) and $A_{\text {net }}\left(8-12 \mu \mathrm{mol} \cdot \mathrm{m}^{-2} \cdot \mathrm{s}^{-1}\right)$ in the $24 / 0 \mathrm{LL}$ treatment were relatively constant (Fig. 4). Although there was a trend towards lower $\mathrm{A}_{\text {net }}$ and higher starch concentrations with increasing photoperiod (Fig. 4), there was no statistical correlation between starch concentration and $\mathrm{A}_{\text {net }}$ of individual leaves $\left(r^{2}=0.129\right)$.

\section{Discussion}

These short-term single leaf studies and whole plant studies (Stutte et al., 1993) suggest that carbon assimilation is maximized at $1100 \mu \mathrm{mol} \cdot \mathrm{mol}^{-1} \mathrm{CO}_{2}$ at both LL and $\mathrm{HL}$ conditions. Dwelle (1985) reported that single leaf $A_{\text {net }}$ was saturated at about 1200 $\mu \mathrm{mol} \cdot \mathrm{m}^{-2} \cdot \mathrm{s}^{-1}$ at ambient $\mathrm{CO}_{2}$ concentrations and that the $\mathrm{A}_{\text {net }}$ values ranged from $14-16 \mu \mathrm{mol} \cdot \mathrm{m}^{-2} \cdot \mathrm{s}^{-1}$, which were consistent with $A_{\text {net }}$ 


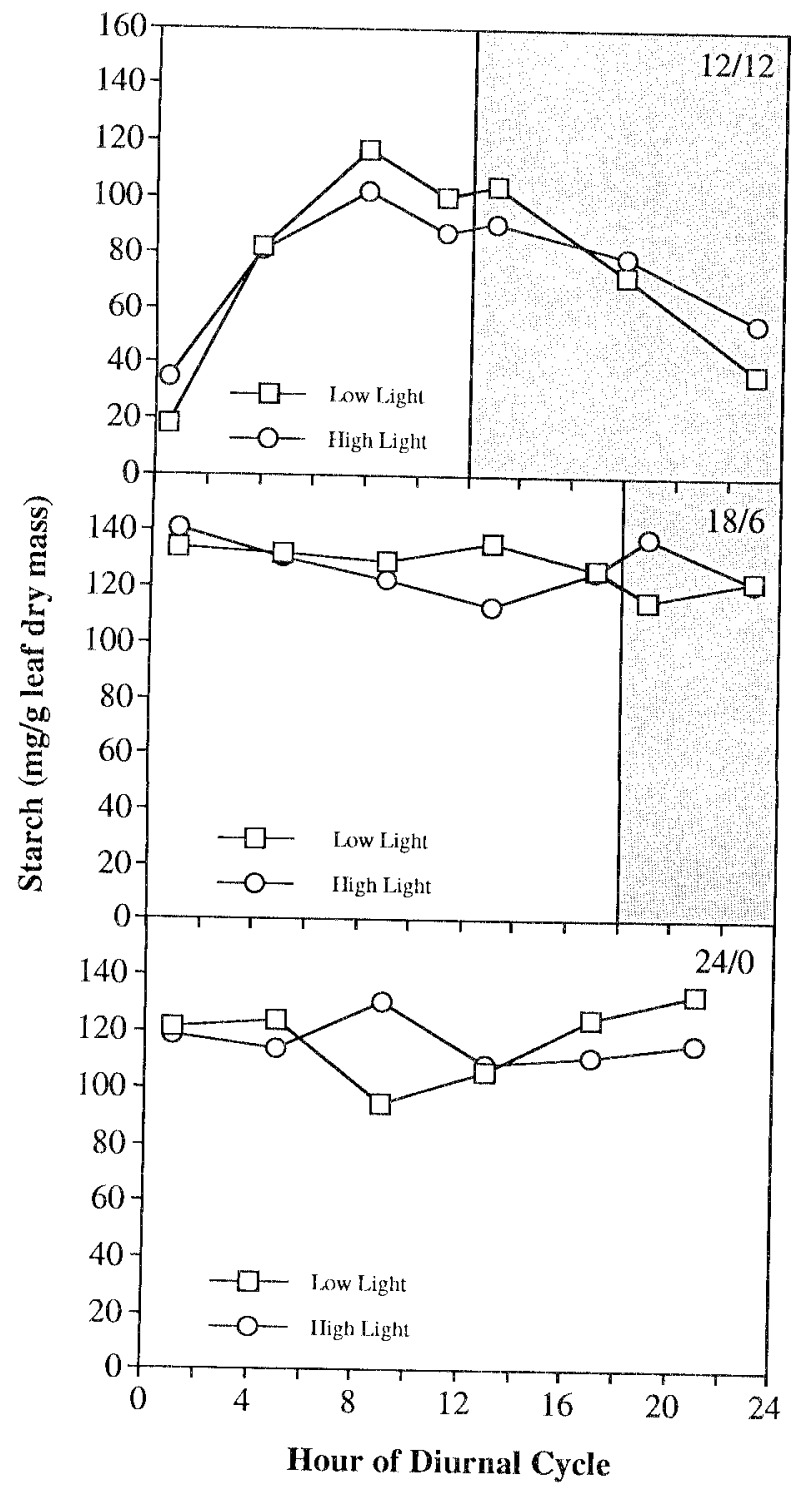

Fig. 3. Effect of PPF on diurnal changes in leaf starch concentration of newly mature 'Norland' potato leaves exposed to different photoperiods. The mean PPF values were 263 and $412 \mu \mathrm{mol} \cdot \mathrm{m}^{-2} \cdot \mathrm{s}^{-1}$ in the low and high light chambers, respectively.

values obtained in these experiments. Light response curves obtained from individual leaves used in these studies indicated that the response was linear $\left(r^{2}=0.961\right)$ over the range tested and that light saturation had not been reached.

There were no significant differences in either $\mathrm{A}_{\text {net }}$ or leaf starch content of measurements obtained in 12/12 treatments, suggesting that the adaptive responses were not associated with age of the plant. This result is consistent with other reports in the literature. Although Wolf (1993) reported that an expanding leaf has greater $\mathrm{A}_{\text {net }}$ and starch content than a fully expanded leaf, in potato, the differences between the recently mature leaves were not statistically significant. Frier (1977) reported that $A_{\text {net }}$ of the first fully expanded leaf increased following tuber initiation but remained constant during tuber bulking. All photoperiod treatments were imposed during this period of tuber bulking.

It should be noted that the photoperiod treatments were imposed on the same plants throughout the experiment, and as a consequence the plants were of different ages when the gas exchange and starch measurements were obtained. However, the short-term photoperiod treatments were started well after the

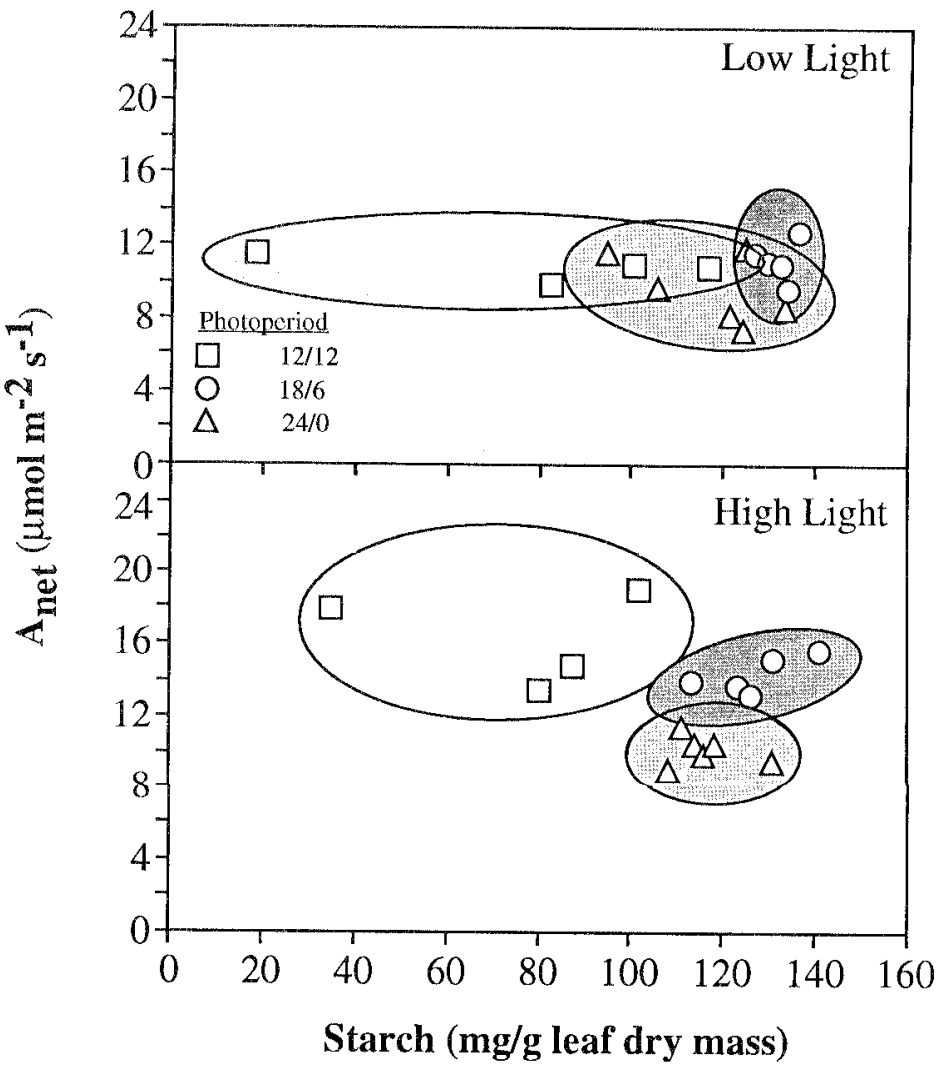

Fig. 4. Effect starch concentration on net carbon assimulation rate of newly mature 'Norland' potato leaves grown in either high or low light conditions. The mean $\mathrm{PPF}$ values were 263 and $412 \mu \mathrm{mol} \cdot \mathrm{m}^{-2} \cdot \mathrm{s}^{-1}$ in the low and high light chambers, respectively.

period of tuber initiation and rapid vegetative development. $A_{\text {net }}$, $\mathrm{A}_{\mathrm{Ci}}$ and leaf starch measurements were obtained from individual leaves that had been returned to $12 / 12$ photoperiod between treatments. The $\mathrm{A}_{\mathrm{net}}$ for the 12/12 PP at 56, 63, and 77 DAP were $13.8,14.1$, and $13.3 \mu \mathrm{mol} \cdot \mathrm{m}^{-2} \cdot \mathrm{s}^{-1}$, respectively, $1 \mathrm{~h}$ after the onset of the light cycle. These values were not significantly different.

Wheeler et al. (1991) grew Norland potatoes in a factorial experiment involving $\mathrm{CO}_{2}$ concentration, photoperiod, and light intensity. Total biomass and yield increased whenever any two variables (photoperiod, $\mathrm{PPF}$, or $\mathrm{CO}_{2}$ concentration) were increased, but declined when all three were increased. This suggests that optimum environmental conditions (e.g., light intensity, photoperiod, and $\mathrm{CO}_{2}$ concentration) derived from short-term experiments are not directly transferable to integrated, long-term production systems. Our results showed a similar, but more pronounced effect. Whenever photoperiod was increased, there was a marked decline in $\mathrm{A}_{\text {net }}$, which was most pronounced under HL conditions. The capacity of the leaves to return to pretreatment $A_{\text {net }}$ and starch levels suggest that the observed responses are physiological and not shock responses.

The maximum starch concentrations were obtained in the HL treatments at shorter photoperiods than the LL treatments. This suggests that $\mathrm{A}_{\text {net }}$ may be an indirect indicator of sink demand, as described under field conditions by Dwelle (1985), but does not appear to correlate with either sink demand or starch storage under more optimal controlled environment conditions. The accumulation of starch in the leaves was not correlated with differences in vascular development between the HL and LL treatments, and is consistent with Moorby (1978), who established that phloem development did not limit tuber bulking of potato.

One must be cautious extrapolating these short-term changes in 
photoperiod to long-duration exposure tests. Increasing the PP from $12 / 12$ to $18 / 6$ resulted in a $16.1 \%$ decrease in $A_{n e t}$, but exposure to continuous lighting resulted in a $33.2 \%$ decrease in $A_{\text {net }}$. Assuming that $A_{\text {net }}$ was at maximum potential in the leaf, increasing PP would initially appear to be an advantage in overall carbon assimilation. Increasing PP from 12/12 to 18/6 under HL conditions would increase the net daily integral ( $\mathrm{mmol} \mathrm{CO}_{2}$ fixed/ $\mathrm{m}^{2}$ per day) from $550 \mathrm{mmol}$ to $735 \mathrm{mmol}$; a $33.7 \%$ increase in total carbon assimilated. Similarly, continuous illumination would result in the daily fixation of $800 \mathrm{mmol}$ of carbon, a $45 \%$ increase over 12/12 photoperiod. However, Norland was unable to sustain these rates of $\mathrm{A}_{\text {net }}$ under long PP in a closed environment without significant tissue damage occurring (Stutte et al., 1993), a result previously reported by Cao and Tibbitts (1991).

'Norland' potato has been successfully grown under conditions of high $\mathrm{CO}_{2}\left(1200 \mu \mathrm{mol} \cdot \mathrm{mol}^{-1}\right)$, high light $\left(690 \mu \mathrm{mol} \cdot \mathrm{m}^{-2} \cdot \mathrm{s}^{-1} \mathrm{PPF}\right)$ and 12/12 photoperiods in the Biomass Production Chamber at Kennedy Space Center (KSC). Preliminary results from one of these tests (Stutte et al., 1993) are consistent with the inability of plants to sustain high levels of $\mathrm{A}_{\text {net }}$ under long photoperiods. About $18 \mathrm{~h}$ into the light cycle (i.e., $6 \mathrm{~h}$ after the former onset of the dark cycle) $\mathrm{A}_{\text {net }}$ began to decline, and continued to decrease at a constant rate until a dark cycle was imposed. The physiological tolerance of the population to continuous light was not reported.

In controlled environments, especially bioregenerative life support systems, the rate of carbon fixation needs to be maximized without damaging plant tissues. The evidence suggests reciprocity between photoperiod and light intensity in the plant's ability to fix and transport carbon. Overall yield increases may be achieved through increased photoperiod if PPF is reduced so that unloading can be maintained. Conversely, light intensity may be increased to achieve higher short term $A_{\text {net }}$ rates if a sufficient dark cycle is provided $(\geq 12 \mathrm{~h})$ for the unloading and transport of starch reserves to occur.

If a physiological limit exists for the fixation and transport of carbon, then increasing photoperiod and light intensity under high $\mathrm{CO}_{2}$ conditions may not be the most appropriate means of maximizing either carbon assimilation or yield in potato. The results reported here suggest that there is a physiological limit to carbon unloading capacity and that 'Norland' potato has short-term mechanisms for feedback control of carbon assimilation. The physiological mechanism of this feedback is unknown, but does not appear to be directly associated with starch storage. These results suggest that total irradiance is not limiting production of potato, as has been suggested by several authors (Salisbury and Bugbee, 1988; Wheeler and Tibbitts, 1987), but that production is limited by the potato leaves ability to either load, or unload the products of photosynthesis.

\section{Literature Cited}

Auchter, E.C. and C.P. Harley. 1924. Effect of various lengths of day on development and chemical composition of some horticultural plants. Proc. Amer. Soc. Hort. Sci. 21:199-214.

Cao, W. and T.W. Tibbitts. 1991. Physiological responses in potato plants under continuous irradiation. J. Amer. Soc. Hort. Sci. 116: 525-527

Dwelle, R.B. 1985. Photosynthesis and photoassimilate partitioning, p. 35-58. In: P.H. Li (ed.). Potato physiolgy Academic Press, Orlando, Fla.
Dwelle, R.B., P.J. Hurley, and J.J. Pavek. 1983. Photosynthesis and stomatal conductance of potato clones (Solanum tuberosum L.). Plant Physiol. 72:172-176.

Frier, V. 1977. The relationship between photosynthesis and tuber growth in Solanum tuberosum L. J. Expt. Bot. 28:999-1007.

Garner, W.W. and H.A. Allard. 1923. Further studies on photoperiodism: The response of plants to relative length of day and night. J. Agr. Res. 23:871-920.

Geiger, D.R. and B.R. Fondy. 1991. Regulation of carbon allocation and partitioning: Status and research agenda, p. 1-9. In: J.L. Bonnemain, S. Delrot, W.J. Lucas, and J.J. Dainty. (eds.). Recent advances in phloem transport and assimilate compartmentation. Ouest ed., Nantes, France. Gregory, L.E. 1965. Physiology of tuberization in plants (tubers and tuberous roots), p. 1328-1354. In: Encyclopedia of plant physiology. vol. 15. Springer-Verlag, Berlin.

Herold, A. 1980., Regulation of photosynthesis by sink activity-The missing link. New Phytol. 86:131-144.

Lorenzen, J.H. and E.E. Ewing. 1992. Starch accumulation in leaves of potato (Solanum tuberosum L.) during the first 18 days of photoperiod treatment. Ann. Bot. 69:481-484

MacElroy, R.D. and J. Bredt. 1985. Current concepts and future direction in CELSS, p. 1-9. In: Life Support Systems in Space Travel. NASA Conf. Publ. 2378, Moffett field, Calif.

McDermitt, D.K., J.M. Norman, J.T. Davis, T.M. Ball, T.J. Arkebauer, J.M. Welles, and S.R. Romer. 1988. $\mathrm{CO}_{2}$ response curves can be measured with a field-portable closed loop photosynthesis system. Proc. Intl. Symp. on forest tree physiology, Nance, France.

Moorby, J., 1978. The physiology of growth and tuber yield, p. 153-95. In: P.M. Harris (ed.). The potato crop: The scientific basis for improvement. Wiley, New York.

Neales, T.F. and L.D. Incoll. 1968. The control of leaf photosynthesis rate by the level of assimilate concentration in the leaf: A review of the hypothesis. Bot. Rev. 34:107-125.

Olson, R.L., M.W. Aleson, and T.J. Slavin. 1988. CELSS for advanced manned missions. HortScience 23:275-286.

Salisbury, F.B. and B.G. Bugbee. 1988. Controlled ecological life support system use of higher plants. NASA Conf. Publ. 2231, Moffett Field, Calif.

Stutte, R.W., R.M. Wheeler, and B.V. Peterson. 1993. Characterization of population $\mathrm{CO}_{2}$ exchange of potato grown in KSC's biomass production chamber. 28:467 (Abstr.)

Tibbitts, T.W., W. Cao, and R.M. Wheeler. 1993. Growth of potatoes for CELSS. Final Rpt.-NCC2-301. NASA Coop. Agreement.

Wang, Z. and G.W. Stutte. 1992. The role of carbohydrates in active osmotic adjustment in apple under water stress. J. Amer. Soc. Hort. Sci. 117:816-823.

Wheeler, R.M., C.L. Mackowiak, J.C. Sager, W.M. Knott, and C.R. Hinkle. 1990. Potato growth and yield using nutrient film technique. Amer. Potato J. 67:177-187.

Wheeler, R.M. and T.W. Tibbitts. 1986a. Utilization of potatoes for life support systems in space. I. Cultivar-photoperiod interactions. Amer. Potato J. 63:315-323

Wheeler, R.M. and T.W. Tibbitts. 1986b. Growth and tuberization of potato (Solanum tuberosum L.) under continuous light. Plant Physiol. 80:801-804

Wheeler, R.M. and T.W. Tibbitts, 1987. Utilization of potatoes for life support systems in space: III. Productivity at successive harvest dates under $12 \mathrm{~h}$ and $24 \mathrm{~h}$ photoperiods. Amer. Potato J. 64:311-320.

Wheeler, R.M., T.W. Tibbitts, and A.H. Fizpatrick. 1991. Carbon dioxide effects on potato growth under different photoperiods and irradiance. Crop Sci. 31:1209-1213.

Wolf, S. 1993. Effect of leaf age on photosynthesis, carbon transport, and carbon allocation in potato plants. Potato Res. 36:253-262. 